\title{
Multifunctional Biodegradable Polymers with Room Temperature Self-Healing and Rewritable Shape Memory Properties via Diels- Alder Reaction
}

\author{
Shenyang Cai ${ }^{\mathrm{a}}$, Zhe Qiang ${ }^{\mathrm{b}}$, Chao Zeng ${ }^{\mathrm{a}}, \mathrm{Jie}^{\mathrm{R}} \mathrm{Ren}^{\mathrm{a}}$ ** \\ ${ }^{a}$ Institute of Nano and Bio-Polymeric Materials, School of Materials Science and Engineering, Tongji University, Shanghai, \\ China, 200092 \\ ${ }^{\mathrm{b}}$ Department of Chemical and Biological Engineering, Northwestern University, Evanston, IL, USA, 60208
}

\section{KEYWORDS. Dynamic crosslinking, poly(lactic acid), block copolymer, biocompatible}

\begin{abstract}
Here, we present a series of novel block copolymers (BCP) from bio-derived monomers, poly(lactic acid)-blockpoly(2,5-furandimethylene succinate) (PLA- $b$-PFS), in which the furan groups from PFS block can be crosslinked with bis(maleimido) triethylene glycol $\left(\mathrm{M}_{2}\right)$ through a Diels-Alder reaction. This dynamic crosslinking reaction leads to a network structure for enhancing the mechanical properties compared to their linear BCP analogous. Decreasing the crosslinking density leads to a decrease of glass transition temperature of BCPs and a transition from glassy to rubbery-like behavior at room temperature. This allows a wide tunablity of both elastic moduli and yields of the materials. For the lowest crosslinking density. the material exhibits an over 50\% self-healing efficiency at room temperature after five days, attributed to the low $\mathrm{T}_{\mathrm{g}}\left(15.2{ }^{\circ} \mathrm{C}\right)$ from the introduction of PFS block, allowing sufficient chain mobility for structure re-organization. Moreover, with the appropriate selection of crosslinking density (PLA- $b-\mathrm{PFS} / \mathrm{M}_{2}(6 / 1)$ ), it also shows an excellent shape memory property with a high recovery rate of $96.3 \%$ and a fixity rate of $97.3 \%$. The permanent shape can be rewriteable due to the reversibility of Diels-Alder reaction. With these advanced functionalities and ease in large-scale fabrication, the PLA- $b$-PFS/M $/ \mathrm{M}_{2}$ shows great promises for self-healing coatings or films with shape memory properties in a wide variety of applications such as packaging materials.
\end{abstract}

\section{INTRODUCTION}

Poly(lactic acid) (PLA), a biodegradable aliphatic polyester that can be produced from microbial fermentation of biomass, has received significant interests in a wide variety of applications including drug delivery, ${ }^{1-2}$ food packing ${ }^{3-4}$ and antibacterial coating. ${ }^{5}$ In general, PLA is mechanically rigid, but its weakness of brittleness, low flexibility and non-recoverable fracture toughness after failure limits its durability and lifetime usages for aforementioned applications. ${ }^{6-7}$ In order to address these challenges for developing mechanically robust (tough) PLA, many strategies have been demonstrated including improving stereochemistry and crystallinity, ${ }^{8-9}$ using plasticizers ${ }^{10-11}$ or nanoparticle fillers ${ }^{12}$ and blending with other polymers with desired material properties such as thermoplastics polyurethane (TPU). ${ }^{13-14}$ Alternatively, using crosslinking also enhances the toughness of PLAs. ${ }^{15}$ Since the traditional chemical crosslinking strategy leads to additional difficulty in materials processing, ${ }^{16}$ the utilization of reversible crosslinks via dynamic covalent chemistries become more attractive, which also enables the materials with self-healing properties for repairing the cracks/damages. ${ }^{17-19}$ Some PLA-based polymers with self-healing properties have been reported based on selfcomplementary quadruple hydrogen bonding. ${ }^{20}$ Another more effective approach is through Diels-Alder (DA) cycloaddition between furan groups and maleimide groups, offering temperature-controllable reversible dynamics. ${ }^{21}$ At room temperature, this reaction leads to a formation of network structures of PLAs from the fm-DA adduct, improving the materials strength and toughness. Upon thermal treatment, the retro DA reaction is favored, allowing a molecular re-arrangement at the fractured polymer surfaces. ${ }^{22}$ Many reports demonstrated the crosslinked thermoplastics via DA chemistry can be used for self-healable materials, ${ }^{17}$, ${ }^{23-24}$ but only few studies associated with PLA or other bio-based materials that can be self-healed at room temperature exist, ${ }^{25}$ mainly due to the glass transition temperature $\left(\mathrm{T}_{\mathrm{g}}\right)$ of segments in polymers (above room temperature ${ }^{26}$ and crystallizing behaviors of PLAs, ${ }^{27-28}$ which the chain mobility of glassy polymer is highly restricted.

Here, we develop a series of novel biodegradable block copolymers from block extension of PLA-OH homopolymers with petroleum-derived monomers, 2,5-furandimethylene succinate (FS). This block copolymer can be crosslinked with 1,8bis(maleimido) triethylene glycol $\left(\mathrm{M}_{2}\right)$ via DA reaction. We report a wide tunability of mechanical properties by varying the crosslinking density and this dynamic crosslinking reaction provides over 50\% self-healing efficiency of polymers at room temperature even without any external stimulus. Furthermore, with appropriate selection of crosslinking density of block copolymers, the material shows an excellent rewritable shape-memory property with a recovery rate of $96.3 \%$ and fixity of $97.3 \%$. 


\title{
EXPERIMENTAL METHODS
}

\begin{abstract}
Materials
5-(hydroxymethyl)furfural (HMF), succinic acid (SA), N,N-dimethyl-4-aminopyridine, 1-lactide, Tin(II) 2-ethylhexanoate (Sn(Oct) 2 ); N,N'-diisopropylcarbodiimide and 1,1-dichloroethene were purchased from Tokyo Chemical Industry. Ethylene glycol, chloroform, methanol and sodium borohydride was purchased from Aldrich. bis(hydroxymethyl)furan (BHF), Poly(2,5-furandimethylene succinate) (PFS) and 1,8-bis-maleimidotriethyleneglycol were synthesized according to previously reports. Other reagents and solvents were purchased from Wako Pure Chemical Industry. All chemicals were used as received.
\end{abstract}

\section{Synthesis of -OH terminated Poly(l-lactide) (PLLA) and Poly(2,5-furandimethylene succinate)- $b$-poly(l-lactide) (PFS- $b$-PLLA)}

L-lactide $(10.0 \mathrm{~g}, 69.4 \mathrm{mmol})$ was fist melt at $120^{\circ} \mathrm{C}$ under a $\mathrm{N}_{2}$ atmosphere and initiated by adding ethylene glyol (0.22 $\left.\mathrm{g}, 3.46 \mathrm{mmol}\right)$ and little amount of catalyst for free radical polymerization. The reaction mixture was stirred at $120^{\circ} \mathrm{C}$ for $24 \mathrm{~h}$. The product was dissolved in chloroform and subsequently precipitated into excess methanol, resulting into a white solid, PLLA. The compound was dried under vacuum at $\mathrm{xx}{ }^{\circ} \mathrm{C}$ for overnight. (PLLA: $9.2 \mathrm{~g}$, yield $92.0 \%, M_{\mathrm{n}}=3200 \mathrm{~g} / \mathrm{mol}\left({ }^{1} \mathrm{H} \mathrm{NMR}\right), M_{\mathrm{n}}=4000 \mathrm{~g} / \mathrm{mol}(\mathrm{GPC}), M_{\mathrm{w}}=5040 \mathrm{~g} / \mathrm{mol}, \mathrm{PDI}=$ 1.26)

For synthesis of PFS- $b$-PLLA, a mixture of $1 \mathrm{~g}$ BHF (7.80 mmol), 0.92/0.94/0.99 g SA (7.8/7.94/8.39 mmol), 0.14/0.56/2.4 g PLLA $(0.035 / 0.14 / 0.56 \mathrm{mmol})$ and $5.70 \mathrm{~g} \mathrm{~N}, N$-dimethyl-4-aminopyridine $(46.7 \mathrm{mmol})$ were dissolved in a $20 \mathrm{~mL}$ of dehydrated dichloromethane under a $\mathrm{N}_{2}$ atmosphere, followed by slowly adding $5.88 \mathrm{~g} \mathrm{~N}, N^{\prime}$-diisopropylcarbodiimide (46.7 mmol) into the mixture. The mixture was stirred at room temperature for $24 \mathrm{~h}$ and dried by evaporation of the solvent. The product was then purified by precipitation from chloroform with excess methanol. The monomer ratio of different blocks (LA/BHF) was controlled at 1/1, 1/4 and 4/1 with a constant $\mathrm{COOH}: \mathrm{OH}$ at 1:1. The volume fraction of different blocks in the block polymers were determined by ${ }^{1} \mathrm{H}$ NMR as listed in Table 1 . PLA and SA copolymer with PLA/SA = 1/1 was also synthesized under the identical condition of block polymers for referencing the chemical structure of block polymers.

\section{Crosslinking of PFS-b-PLLA with bis-maleimide (PFS/M).}

Mixture of PFSLA and bis-maleimide (F/M ratio = 2/1, 3/1, 4/1 or 6/1) were prepared as films cast from chloroform solution. After drying, films were compression-molded between two Teflon sheets with an aluminum spacer ( $0.2 \mathrm{~mm}$ thickness) using a hot press (Imoto, Japan) at $130{ }^{\circ} \mathrm{C}$ for 5 min under a pressure of $5 \mathrm{MPa}$. The samples was quenched to $40^{\circ} \mathrm{C}$, held at this tempsrature for $3 \mathrm{~h}$, and then held at room temperature at least $24 \mathrm{~h}$.

\section{Characterization}

${ }^{1} \mathrm{H}$ NMR and ${ }^{13} \mathrm{C}$ NMR were performed in $\mathrm{CDCl}_{3}$ solution on a JEOL JNM-AL400 spectrometer at $400 \mathrm{MHz}$. Gel permeation chromatography (GPC) was carried out with a Tosoh HLC-8220GPC equipped with two Shodex GPC LF-804 columns. Polystyrene standards with low polydispersity were used to construct a calibration curve. Attenuated total reflection infrared (ATR-IR) spectra were obtained with a Thermo Scientific Nicolet iS10 FT-IR spectrometer equipped with a ZnSe crystal on Smart iTR. IR spectra were recorded over a wavenumber range of 3800-600 cm-1 with $2 \mathrm{~cm}^{-1}$ resolution for xx scans. The absorption peaks were deconvoluted using the Fit Multiple Peak tool from OriginPro 8 software (OriginLab Corporation). Differential scanning calorimetry (DSC) was carried out on a Seiko EXSTAR6000 equipped with a DSC6220N. Samples of $2-5 \mathrm{mg}$ in an aluminum pan were analyzed from $-60{ }^{\circ} \mathrm{C}$ to $150{ }^{\circ} \mathrm{C}$ or $200{ }^{\circ} \mathrm{C}$ at a heating ramp of $10^{\circ} \mathrm{C} \mathrm{min}-1$ under a $\mathrm{N}_{2}$ atmosphere. The mechanical properties of polymer samples were determined using a Shimadzu EZ test tensile testing machine at a cross-head speed of $5 \mathrm{~mm} \mathrm{~min}^{-1}$ at room temperature. No.2 (1/5) dumbbell shaped specimens described in JIS K 7113 (active region: $7.0 \mathrm{~mm} \times 1.4 \mathrm{~mm} \times 0.3-0.4 \mathrm{~mm}$ ) were used. Each measurement was repeated at least four times and the average values were reported in order to ensure the reproducibility of data. Dynamic mechanical analysis (DMA) was carried out with a SII EXSTAR DMS6100 under the controlled force mode for determining the shape memory properties. The polymer is deformed at an elevated temperature (deformation temperature, $T_{\mathrm{d}}$ ) and the deformed temporary shape is fixed upon cooling (fixing temperature, $T_{\mathrm{f}}$ ). It is then heated to a recovery temperature $\left(T_{\mathrm{r}}\right)$ to recover the permanent shape. The sample was first kept at $30{ }^{\circ} \mathrm{C}$ for several min and then stretched at $0.2 \mathrm{~N} / \mathrm{min}$ until $0.6 \mathrm{~N}$. The DMA chamber was then cooled to $0{ }^{\circ} \mathrm{C}$ while maintaining the applied stress for $20 \mathrm{~min}$. Then, the sample was unloaded and kept at $0{ }^{\circ} \mathrm{C}$ for about $20 \mathrm{~min}$ to fix the temporary shape. Finally, the sample was heated to $30{ }^{\circ} \mathrm{C}$ and kept isothermal for $20 \mathrm{~min}$ to recover the permanent shape. In self-healing experiments, dumbbell specimens were first broken by the tensile test. The two broken surfaces were then immediately reunited with a gentle pressure and stored horizontally at room temperature for 5 days without any pressure or external stimulus.

\section{RESULTS AND DISCUSSION}

The strategy for the synthesis of bis(maleimido) triethylene glycol crosslinked poly(lactic acid)-block-poly(2,5-furandimethylene succinate) (PLA- $b$-PFS/M $/ \mathrm{M}_{2}$ ) involves three steps, as shown in scheme 1. (1) The hydroxyl (-OH) terminated PLA was first prepared through a ring-open polymerization with the presence of ethylene glycol and catalysts; ${ }^{29}(2)$ the second block (PFS) was then extended onto the PLA backbones with random copolymerization of two monomers (bis(hydroxymethyl) furan (BHF) and succinic 
acid (SA)) under different molar ratios (BHF:SA=1:4; 1:1 and 4:1) (3) The furan group from BHF can be then reacted with 1,8bis(maleimido) triethylene glycol $\left(\mathrm{M}_{2}\right)$ through Diels-Alder (DA) reaction, leading to crosslinked network structures. The crosslinking density can be manipulated by varying the molar ratio of BCP (PLA- $b$-PFS) to $\mathrm{M}_{2}(2 / 1 ; 3 / 1 ; 4 / 1$ and $6 / 1$ in this study). The ease in these synthetic steps provides the opportunity for large-scale fabrication of these multi-functional biodegradable materials.

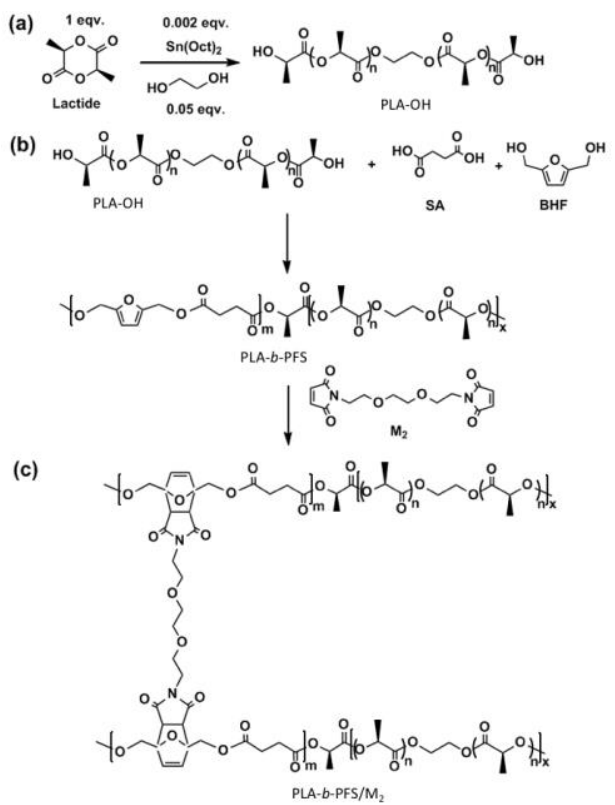

Scheme 1. Synthesis route of (a) -OH terminated PLA, (b) PLA- $b$-PFS and (c) crosslinking of PLA- $b$-PFS by M $_{2}$.

The chemical structures of as-synthesized PLA and PLA- $b$-PFS was first confirmed by ${ }^{13} \mathrm{C}$ NMR as shown in Figure 1 (a) with each peak assigned to its corresponding chemical group. The peak at $169.5 \mathrm{ppm}$ is from carbonyl groups of PLA block, which can be used to determine the sequence distribution of repeating unit. The area of $\mathrm{g}$ peaks from PFS block gradually decreases with increasing LA content. We have determined the volume fraction of each block in the PLA- $b$-PFS from ${ }^{13} \mathrm{C}$ NMR spectra as shown in Table 1. Figure 1(b) shows that the chemical shift of $\mathrm{C}=\mathrm{O}$ at $171.7 \mathrm{ppm}$ splits into three peaks $\left(\mathrm{g}_{+}+\mathrm{g}_{2}, \mathrm{~g}_{1}, \mathrm{~g}_{3}\right)$, corresponding to the sequence of block structures. Peak of $\mathrm{g}_{1}$ and $\mathrm{g}_{3}$ is much more obvious in higher PLA content BCPs (PFS-b-PLA (1/1) and PFS-bPLA (1/4)) compared to PFS- $b$-PLA (4/1) and PFS, suggesting that both peaks (g1 and g3) can be attributed to the existence of SA units in both blocks (succinic acid in PFS or lactic acid in PLA). DSC thermograms of these block copolymers are shown in Figure 1(c). With the introduction of PFS block $\left(\mathrm{T}_{\mathrm{g}}=15.4{ }^{\circ} \mathrm{C}\right.$ ), the $\mathrm{T}_{\mathrm{g}}$ of the block copolymers decreases from $44.9{ }^{\circ} \mathrm{C}$ (homopolymer PLA$\mathrm{OH})$ to $16.2{ }^{\circ} \mathrm{C}$ (below room temperature) when the molar ratio of PFS to PLA is 4:1. This block copolymer (PLA-b-PFS (1/4)) is selected to be crosslinked with $\mathrm{M}_{2}$ via DA reaction for the rest of this study, as illustrated in Figure 1(d). The DA reaction between furan groups (from BHF) and maleimide groups effectively provides the crosslinking sites to form network structures.

(a)

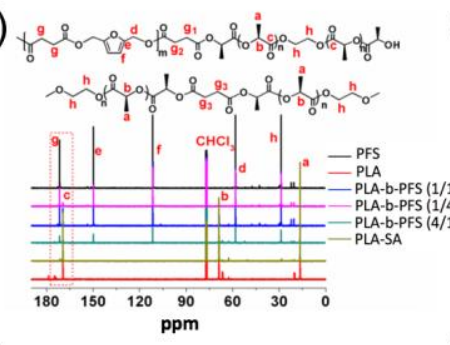

(c)

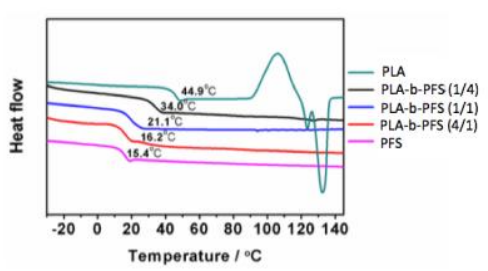

(b)

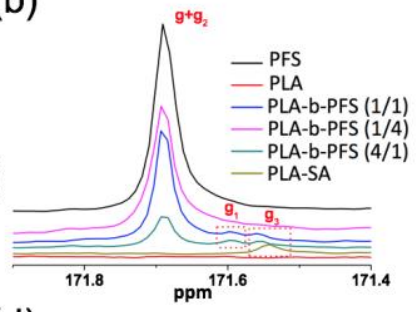

(d)

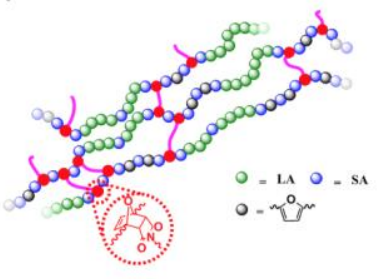


Figure 1. (a) ${ }^{13} \mathrm{C}$ NMR spectra of PFS, PLA and PLA- $b$-PFS polymers and (b) its magnified spectra at the region of 171.4-171.9 ppm. (c) DSC curves of PLA, PFS and PLA- $b$-PFS with different molar ratio of LA to FS and (d) a schematic illustration of PLA$b$-PFS crosslinked by $\mathrm{M}_{2}$ through DA reaction.
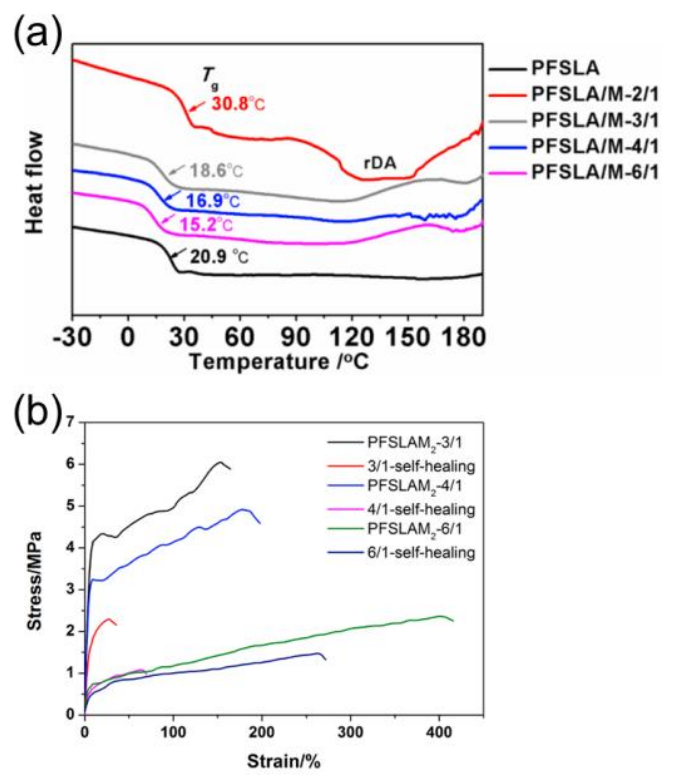

Figure 2. (a) DSC curves of PLA- $b$-PFS/M $\mathrm{M}_{2}$ with different crosslinking density and (b) comparison of stress-strain curves for PFS-b$\mathrm{PLA} / \mathrm{M}_{2}$ at various crosslinking density and its self-healed (after 5 days) analogs.

\begin{tabular}{lcccccc}
\hline \multicolumn{1}{c}{ Samples } & BHF & LA & SA & $\boldsymbol{M}_{\mathbf{n}} / \mathbf{g ~ m o l}^{-\mathbf{1}}$ & PDI & Yield / \% \\
\hline PFSLA-4/1 & $42.4 \%$ & $12 \%$ & $43.6 \%$ & 5000 & 1.82 & 52 \\
PFSLA-1/1 & $30.8 \%$ & $36.6 \%$ & $32.6 \%$ & 9400 & 1.36 & 78 \\
PFSLA-1/4 & $14 \%$ & $69.4 \%$ & $16.6 \%$ & 14600 & 1.63 & 85 \\
PLLA/SA & N/A & $84 \%$ & $16 \%$ & 23000 & 1.38 & 93 \\
\hline Table 1. Volume fraction of different repeating unit composition and molecular weight results of block polymers
\end{tabular}

Interestingly, after crosslinking, the $\mathrm{T}_{\mathrm{g}}$ (Figure 2(a)) has been depressed from $20.9{ }^{\circ} \mathrm{C}$ to $15.2{ }^{\circ} \mathrm{C}$ at the lowest crosslinking density of $6: 1$. This is may due to the disturbance of PFS chain packing by the linkers, which the crosslinking reaction increases the free volume between the PFS molecules, similar with the pervious observation from reported study ${ }^{30}$. Additionally, the crosslinkers are chemically very similar to short PEO chains, which will increase the chain flexibility and alead to a decrease in glass transition temperature. ${ }^{31}$ Further increasing the crosslinking density, the $\mathrm{T}_{\mathrm{g}}$ increases to $16.9{ }^{\circ} \mathrm{C}(4 / 1)$ to $18.6{ }^{\circ} \mathrm{C}(3 / 1)$ and $30.8{ }^{\circ} \mathrm{C}$ at the highest crosslinking density of $2 / 1$. These results indicate tunability of $\mathrm{T}_{\mathrm{g}}$ (below or above room temperature) for desired properties by varying the crosslinking density. Figure 2(b) shows the stress-strain curves of PLA- $b$-PFS/ $\mathrm{M}_{2}$ for different crosslinking densities varying from $2 / 1$ to $6 / 1$. With the highest crosslinking density, the material shows a Young's modulus of approximately $1800 \mathrm{MPa}$ and low elongation break of approximately $40 \%$, which is consistent with its glassy behavior of polymeric materials at room temperature. Decreasing the crosslinking density leads a decrease in modulus and a significant improvement in elongation break (beyond 400\%) when the crosslinking ratio is 6:1 (PLA-b-PFS : $\mathrm{M}_{2}$ ). In this case, the significantly different mechanical behaviors for highest crosslinking density samples and the others are attributed to the shift of the BCPs from glassy state to rubbery state at room temperature. The self-healing behavior of crosslinked systems were investigated at room temperature. The samples were first broken up and allowed self-recovery for 5 days. When the PLA- $b$-PFS : $\mathbf{M}_{2}$ is $2 / 1$ (highest crosslinked system) or 4/1, the evidence of self-healing properties cannot be observed from both optical images (Figure S2) and stress-strain curves. With lowest crosslinking density, the material shows recovery in elongation $(65.2 \%)$ and in tensile strength $(61.7 \%)$ attributed to its low $\mathrm{T}_{\mathrm{g}}$, enabling local re-organization of rubber-behavior polymer chains at room temperature without any external stimulus. This selfrecovery can also be revealed by the optical images where the crack from breaking is healed. Furthermore, the unreacted maleimide groups at the broken surface could crosslinking with other unreacted furan groups for re-formation and generatation networking 
structures. It is also expected that the volume fraction of PFS in block copolymer structures will also affect self-healing properties as this is the component from providing free furan groups for reacting with maleimide groups. With higher content of PFS, a better self-healing performance should be obtained.

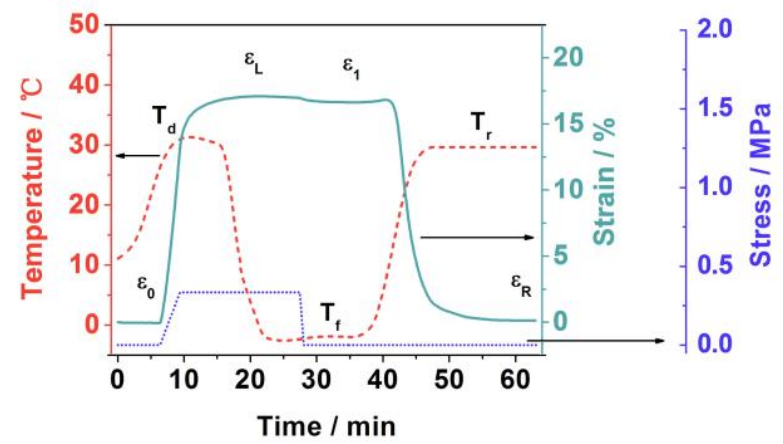

Figure 3. Shape memory properties of PFS-b-PLA/M $\mathrm{M}_{2}(6 / 1)$ at a deformation temperature of $30{ }^{\circ} \mathrm{C}$ and recovery temperature of $30 \mathrm{C}$ and at a fixing temperature of $0{ }^{\circ} \mathrm{C}$.

The shape memory property of PLA- $b$-PFS/M $\mathrm{M}_{2}(6 / 1)$ was investigated tension with stress-control using dynamic mechanical analysis (DMA), as shown in Figure 3. An initial cycle was performed in order to minimize the underlying creep of materials during testing, at elevated temperature. The sample was first deformed at $30{ }^{\circ} \mathrm{C}$ with approximately $18 \%$ strain, and followed by a quick quench to $-5{ }^{\circ} \mathrm{C}$ in order to maintain its temporary shape. After release of the stress at room temperature $\left(25^{\circ} \mathrm{C}\right)$, the fixity of $97.3 \%$ is obtained after 20 min. Followed by heating the sample back to $30{ }^{\circ} \mathrm{C}$, the strain almost decreases back to $0 \%$ after 5 min, indicating its recovery to the original shape. The recovery rate $\left(\mathrm{R}_{\mathrm{r}}\right)$ from DMA is determined to be $96.3 \%$, demonstrating its good shape-memory property.

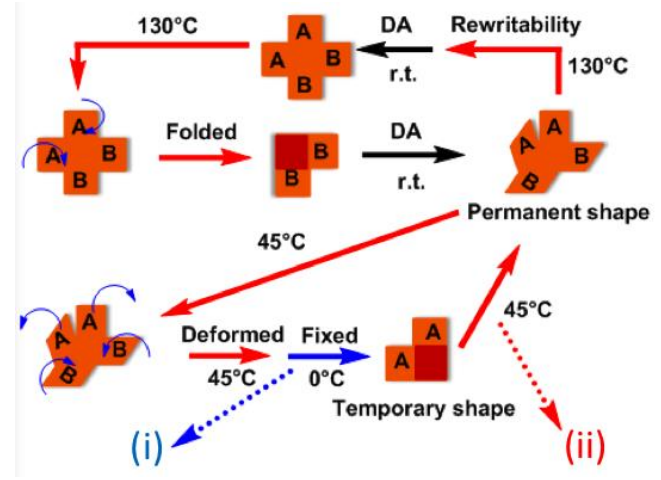

(i) (ii)

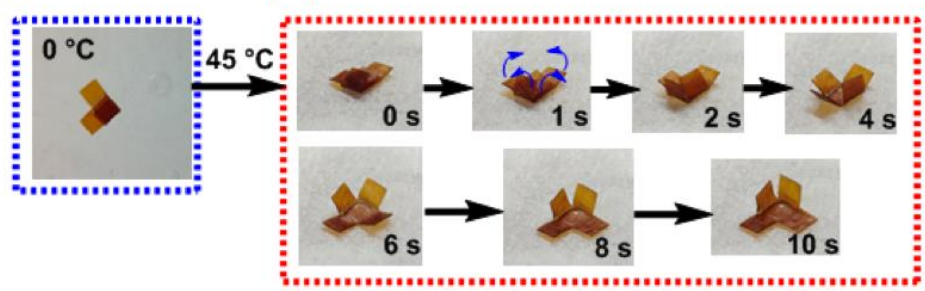

Figure 4. Preparation of sample for shape memory test and shape transformation of PFSLA/M $\mathrm{M}_{2}-6 / 1$ with rewritable functionality.

The crosslinking from reversible DA reaction also enables rewritable polymers with shape-memory functions at elevated temperatures as shown in Figure 4. PLA- $b$-PFS/M $\mathrm{M}_{2}$ (6-1) was first compressed into a thick film and then cut into a cross-like shape. After the sample was heat up to $130{ }^{\circ} \mathrm{C}$, the region A of films was folded with region B remained intact. Then the sample was quenched at $40^{\circ} \mathrm{C}$ for $3 \mathrm{~h}$, followed by placing at room temperatures for 3 days, allowing DA reactions for obtaining the permanent shape, as shown in Figure 4. For investigating the programmable shape memory property, the PLA- $b$-PFS/M 2 (6-1) film was first deformed from its permanent shape to its temporary shape at $T_{\mathrm{d}}=45^{\circ} \mathrm{C}$, held in its deformed shape, and subsequently cooled to 0 ${ }^{\circ} \mathrm{C}$ in the ice bath (below $T_{\mathrm{g}}$ ) for $5 \mathrm{~min}$. After fixation of the deformed temporary shape was complete, the load force was removed. In the recovery process, the PFSLA/M $\mathrm{M}_{2}$ film was heated at $45^{\circ} \mathrm{C}$ to trigger the transformation from temporary shape to permanent shape. We noted that A, B regions show different recovery behaviors/responses at the same temperature that above $T_{\mathrm{g}}$ while their mechanism are the same. Figure 4 also shows the visual images of PFSLA/M $\mathrm{M}_{2}$ film during the entire recovery process with completely opposite recovery directions from A and B regions due to their differences in original permeant shape. After the shape memory test, the initial permanent shape (first cycle) of samples can be rewritten to change into other shapes after a simple heating process. It is indicated that the permanent shape of different regions of polymer film can be designed and rewritable via DA and retro DA reaction depending on the needs of the specific application which offers the polymer with more choices of shape changing.

In conclusion, poly(2,5-furandimethylene succinate-b-lactide) block polymer was obtained from bio-based monomer, (lactide, SA and HMF). The block polymers can be cross-linked by bismaleimide via Diels-Alder reaction. By controlling the furan/maleimide ratio in polymers, mechanical properties were varied widely. The polymers displayed self-healing ability without external stimulus as well as well shape memory property with a recovery rate of $96.3 \%$ and a fixity rate of $97.3 \%$. The permanent shape of different regions of polymer film can be designed and rewritable which offers for desired shape changing by one-step processing. Such PLA- 
based block polymers could have high potential applications as biomedical implant materials, engineering plastics and aerospace materials,

\section{ASSOCIATED CONTENT}

\section{Supporting Information}

The Supporting Information is available free of charge on the ACS Publications website.

\section{AUTHOR INFORMATION}

\section{Corresponding Author}

*J.Ren: renjie65@163.com

\section{Author Contributions}

The manuscript was written through contributions of all authors

\section{ACKNOWLEDGMENT}

The authors thank Naoko Yoshie for helpful discussion. The authors acknowledge the China Scholarship Council (CSC) in this research.

\section{REFERENCES}

(1) Zhu, D. W.; Tao, W.; Zhang, H. L.; Liu, G.; Wang, T.; Zhang, L. H.; Zeng, X. W.; Mei, L., Docetaxel (DTX)-loaded polydopaminemodified TPGS-PLA nanoparticles as a targeted drug delivery system fore the treatment of liver cancer. Acta Biomaterialia 2016, 30, 144154.

(2) Cho, H.; Gao, J. M.; Kwon, G. S., PEG-b-PLA micelles and PLGA-b-PEG-b-PLGA sol-gels for drug delivery. Journal of Controlled Release 2016, 240, 191-201.

(3) Auras, R. A.; Singh, S. P.; Singh, J. J., Evaluation of oriented poly(lactide) polymers vs. existing PET and oriented PS for fresh food service containers. Packag. Technol. Sci. 2005, 18, 207-216.

(4) Bai, H. W.; Huang, C. M.; Xiu, H.; Zhang, Q.; Deng, H.; Wang, K.; Chen, F.; Fu, Q., Significantly Improving Oxygen Barrier Properties of Polylactide via Constructing Parallel-Aligned Shish-Kebab-Like Crystals with Well-Interlocked Boundaries. Biomacromolecules 2014, 15, 1507-1514.

(5) Guillaume, O.; Garric, X.; Lavigne, J. P.; Van Den Berghe, H.; Coudane, J., Multilayer, degradable coating as a carrier for the sustained release of antibiotics: Preparation and antimicrobial efficacy in vitro. Journal of Controlled Release 2012, 162, $492-501$.

(6) Nampoothiri, K. M.; Nair, N. R.; John, R. P., An overview of the recent developments in polylactide (PLA) research. Bioresour. Technol. 2010, 101, 8493-8501.

(7) Thurber, C. M.; Xu, Y.; Myers, J. C.; Lodge, T. P.; Macosko, C. W., Accelerating Reactive Compatibilization of PE/PLA Blends by an Interfacially Localized Catalyst. ACS Macro Lett. 2015, 4, 30-33.

(8) Gao, A. L.; Zhao, Y. Q.; Yang, Q.; Fu, Y. Y.; Xue, L. X., Facile preparation of patterned petal-like PLA surfaces with tunable water micro-droplet adhesion properties based on stereo-complex co-crystallization from non-solvent induced phase separation processes. $J$. Mater. Chem. A 2016, 4, 12058-12064.

(9) Horeglad, P.; Litwinska, A.; Zukowska, G. Z.; Kubicki, D.; Szczepaniak, G.; Dranka, M.; Zachara, J., The influence of organosuperbases on the structure and activity of dialkylgallium alkoxides in the polymerization of rac-lactide: the road to stereo diblock PLA copolymers. Appl. Organomet. Chem. 2013, 27, 328-336.

(10) Hassouna, F.; Raquez, J. M.; Addiego, F.; Dubois, P.; Toniazzo, V.; Ruch, D., New approach on the development of plasticized polylactide (PLA): Grafting of poly(ethylene glycol) (PEG) via reactive extrusion. European Polymer Journal 2011, 47, $2134-2144$.

(11) Cai, S.; Sun, Y.-C.; Ren, J.; Naguib, H. E., Toward the low actuation temperature of flexible shape memory polymer composites with room temperature deformability via induced plasticizing effect. Journal of Materials Chemistry B 2017, 5, 8845-8853.

(12) Oksman, K.; Skrifvars, M.; Selin, J. F., Natural fibres as reinforcement in polylactic acid (PLA) composites. Compos. Sci. Technol. 2003, 63, 1317-1324.

(13) Lai, S. M.; Lan, Y. C., Shape memory properties of melt-blended polylactic acid (PLA)/thermoplastic polyurethane (TPU) bio-based blends. J. Polym. Res. 2013, 20, 1-8.

(14) Dogan, S. K.; Reyes, E. A.; Rastogi, S.; Ozkoc, G., Reactive Compatibilization of PLA/ TPU Blends with a Diisocyanate. Journal of Applied Polymer Science 2014, 131, 10.

(15) Li, X.; Kang, H. L.; Shen, J. X.; Zhang, L. Q.; Nishi, T.; Ito, K.; Zhao, C. M.; Coates, P., Highly toughened polylactide with novel sliding graft copolymer by in situ reactive compatibilization, crosslinking and chain extension. Polymer 2014, 55, 4313-4323. 
(16) Chen, X.; Zhang, N. W.; Gu, S. Y.; Li, J. B.; Ren, J., Preparation and properties of ramie fabric-reinforced thermoset poly lactic acid composites. Journal of Reinforced Plastics and Composites 2014, 33, 953-963.

(17) Liu, Y. L.; Chuo, T. W., Self-healing polymers based on thermally reversible Diels-Alder chemistry. Polym. Chem. 2013, 4, 21942205.

(18) Li, C. H.; Wang, C.; Keplinger, C.; Zuo, J. L.; Jin, L.; Sun, Y.; Zheng, P.; Cao, Y.; Lissel, F.; Linder, C.; You, X. Z.; Bao, Z. A., A highly stretchable autonomous self-healing elastomer. Nat. Chem. 2016, 8, 619-625.

(19) Wang, C.; Liu, N.; Allen, R.; Tok, J. B. H.; Wu, Y. P.; Zhang, F.; Chen, Y. S.; Bao, Z. N., A Rapid and Efficient Self-Healing Thermo-Reversible Elastomer Crosslinked with Graphene Oxide. Advanced Materials 2013, 25, 5785-+.

(20) Chang, R. X.; Huang, Y. F.; Shan, G. R.; Bao, Y. Z.; Yun, X. Y.; Dong, T. L.; Pan, P. J., Alternating poly(lactic acid)/poly(ethyleneco-butylene) supramolecular multiblock copolymers with tunable shape memory and self-healing properties. Polym. Chem. 2015, 6, 58995910 .

(21) Zeng, C.; Seino, H.; Ren, J.; Hatanaka, K.; Yoshie, N., Bio-Based Furan Polymers with Self-Healing Ability. Macromolecules 2013, 46, 1794-1802.

(22) Hsu, Y. I.; Masutani, K.; Yamaoka, T.; Kimura, Y., Strengthening of hydrogels made from enantiomeric block copolymers of polylactide (PLA) and poly(ethylene glycol) (PEG) by the chain extending Diels-Alder reaction at the hydrophilic PEG terminals. Polymer 2015, 67, 157-166.

(23) Oehlenschlaeger, K. K.; Mueller, J. O.; Brandt, J.; Hilf, S.; Lederer, A.; Wilhelm, M.; Graf, R.; Coote, M. L.; Schmidt, F. G.; BarnerKowollik, C., Adaptable Hetero Diels-Alder Networks for Fast Self-Healing under Mild Conditions. Advanced Materials 2014, 26, 35613566.

(24) Bai, N.; Saito, K.; Simon, G. P., Synthesis of a diamine cross-linker containing Diels-Alder adducts to produce self-healing thermosetting epoxy polymer from a widely used epoxy monomer. Polym. Chem. 2013, 4, 724-730.

(25) Wertz, J. T.; Mauldin, T. C.; Boday, D. J., Polylactic Acid with Improved Heat Deflection Temperatures and Self-Healing Properties for Durable Goods Applications. ACS Appl. Mater. Interfaces 2014, 6, 18511-18516.

(26) Wang, Y.; Ribelles, J. L. G.; Sanchez, M. S.; Mano, J. F., Morphological contributions to glass transition in poly(L-lactic acid). Macromolecules 2005, 38, 4712-4718.

(27) Saeidlou, S.; Huneault, M. A.; Li, H. B.; Park, C. B., Poly(lactic acid) crystallization. Progress in Polymer Science 2012, 37, 16571677.

(28) Kawai, T.; Rahman, N.; Matsuba, G.; Nishida, K.; Kanaya, T.; Nakano, M.; Okamoto, H.; Kawada, J.; Usuki, A.; Honma, N.; Nakajima, K.; Matsuda, M., Crystallization and melting behavior of poly (L-lactic acid). Macromolecules 2007, 40, 9463-9469.

(29) Agatemor, C.; Shaver, M. P., Tacticity-Induced Changes in the Micellization and Degradation Properties of Poly(lactic acid)-blockpoly(ethylene glycol) Copolymers. Biomacromolecules 2013, 14, 699-708.

(30) Zeng, C.; Seino, H.; Ren, J.; Hatanaka, K.; Yoshie, N., Self-healing bio-based furan polymers cross-linked with various bismaleimides. Polymer 2013, 54, 5351-5357.

(31) Choi, U. H.; Liang, S. W.; Chen, Q.; Runt, J.; Colby, R. H., Segmental Dynamics and Dielectric Constant of Polysiloxane Polar Copolymers as Plasticizers for Polymer Electrolytes. ACS Appl. Mater. Interfaces 2016, 8, 3215-3225. 


\section{Insert Table of Content (TOC)}

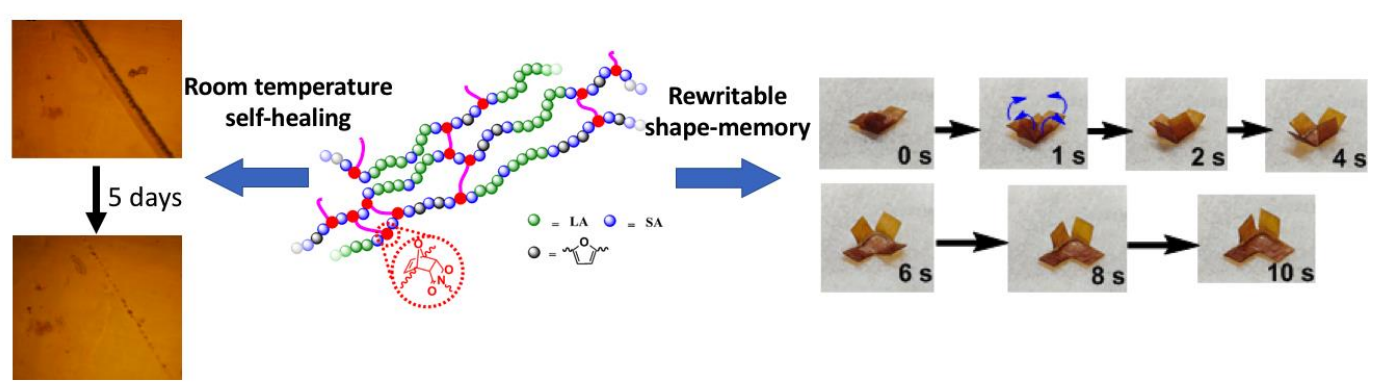

